\title{
Thermal cycling as a novel thermal therapy to synergistically enhance the anticancer effect of propolis on PANC-1 cells
}

\author{
WEI-TING CHEN ${ }^{1,2}$, YI-KUN SUN ${ }^{2}$, CHUEH-HSUAN LU ${ }^{1,2}$ and CHIH-YU CHAO ${ }^{1-3}$ \\ ${ }^{1}$ Department of Physics, Laboratory for Medical Physics and Biomedical Engineering, National Taiwan University, \\ Taipei 10617; ${ }^{2}$ Biomedical and Molecular Imaging Center, National Taiwan University College of Medicine, Taipei 10051; \\ ${ }^{3}$ Institute of Applied Physics, National Taiwan University, Taipei 10617, Taiwan, R.O.C.
}

Received January 30, 2019; Accepted July 1, 2019

DOI: $10.3892 /$ ijo.2019.4844

\begin{abstract}
Hyperthermia (HT) has shown potential in cancer therapy. In particular, it appears to sensitize cancer cells to chemotherapy. However, a major concern associated with HT is that the thermal dosage applied to the tumor cells may also harm the normal tissue cells. Besides, the drugs used in HT are conventional chemotherapy drugs, which may cause serious side effects. The present study demonstrated a novel methodology in HT therapy called thermal cycle (TC)-HT. With this strategy, a therapeutic window with a maximum synergistic effect was created by combining TC-HT with natural compounds, with minimal unwanted cell damage. The natural compound propolis was selected, and the synergistic anticancer effect of TC-HT and propolis was investigated in pancreatic cancer cells. The present results demonstrated for the first time that TC-HT could enhance the anticancer effect of propolis on PANC-1 cancer cells through the mitochondria-dependent apoptosis pathway and cell cycle arrest. Combined treatment greatly suppressed mitochondrial membrane potential, which is an important indicator of damaged and dysfunctional mitochondria. Furthermore, the cell cycle-regulating protein cell division cycle protein 2 was downregulated upon combined treatment, which prevented cellular progression into mitosis. The present study offers the first report, to the best of our knowledge, on the combination of TC-HT with a natural compound for pancreatic cancer treatment. It is anticipated that this methodology may be a starting point for more sophisticated cancer treatments and may thereby improve the quality of life of many patients with cancer.
\end{abstract}

Correspondence to: Dr Chih-Yu Chao, Department of Physics, Laboratory for Medical Physics and Biomedical Engineering, National Taiwan University, No. 1, Sec. 4, Roosevelt Road, Taipei 10617, Taiwan, R.O.C.

E-mail: cychao@phys.ntu.edu.tw

Key words: combination treatment, synergistic effect, hyperthermia, pancreatic cancer, propolis

\section{Introduction}

Temperature serves an important role in regulating biological reactions. The human body has the remarkable ability to maintain its core temperature between 36.5 and $37.5^{\circ} \mathrm{C}$. Occasionally, the body raises its temperature to support the immune system, making the environment less favorable for replicating viruses and bacteria. Scientists have been interested in the profound effects of heat on cells for a long time, and have utilized it in various types of therapies. The most popular, called hyperthermia (HT) therapy, is used in the treatment of cancer. Multiple attempts have been made to uncover the biological effects of HT on tumors in recent years (1-3). Although the treatment of cancer with HT has been explored in previous studies (4-6), research on the effect of HT alone as a cancer treatment is limited.

Previous results indicated that a direct cancer cell killing effect could occur when cells were heated to $>42^{\circ} \mathrm{C}$ for $\geq 1 \mathrm{~h}$ (1). This made HT less feasible in clinical treatment, since damage to the central nervous system occurs within a few minutes of exposure to $42^{\circ} \mathrm{C}(7)$. Therefore, a second line of HT research, which focused on its use in combination with chemotherapy or radiotherapy, quickly emerged (8). Previous clinical trials or in vitro studies showed that HT improves the effect of anticancer drugs and radiation (9-11). For example, Schaaf et al (8) demonstrated that HT synergizes with cisplatin or doxorubicin by inhibiting poly(ADP)-ribose polymerase (PARP)1-dependent DNA replication arrest. Mild HT also improves drug delivery by breaking the stromal barrier in pancreatic cancer xenograft mouse models and sensitizes cancer cells to PARP1 inhibition $(9,12)$. These studies suggested that HT could be an adjuvant method to cancer chemotherapy. However, little attention has been paid to discussing the optimal treatment temperature and time sequences that provide the maximum potentiating effects and the minimum unwanted cell damage. Mild HT could have limited potentiating effects, while too high temperatures may cause unwanted cell damage. In fact, previous in vitro studies revealed that HT is not tumor selective and could also damage normal tissue cells $(7,13)$. Therefore, it is of utmost importance to select the correct temperature and duration so that the combination of HT and chemotherapeutic drugs can provide an optimal anticancer effect while minimizing the unwanted 
cell damage caused by HT. Furthermore, the drugs used in HT combination therapies are conventional chemotherapy drugs, which may also cause serious side effects. There is currently an emerging area of research on cancer prevention and cure focused on natural compounds, particularly dietary products, due to their low toxicity and potent efficacy. The present study focused on the effects of propolis, which is a resinous substance produced by honeybees. It has historically been used to treat or alleviate several maladies in traditional medicine (14-16), and it has been the focus of numerous studies due to its anticancer, anti-inflammatory and antioxidant activities (17-19). Frión-Herrera et al (20) reported that Brazilian propolis induced apoptosis in human lung cancer A549 cells through the mitochondria-mediated pathway. Demir et al (21) also demonstrated the antiproliferative and proapoptotic activity of propolis on human lung cancer cells. Therefore, the objective of the present study was to investigate the synergistic anticancer effect of thermal cycle (TC)-HT and propolis.

The present study reports a refined method of cycling high and low temperatures to achieve a synergistic anticancer effect with natural compounds while minimizing the damage caused by HT. In this strategy, high temperatures markedly enhance the anticancer effect of the natural compounds while the cooling process prevents cell damage caused by an excessive thermal dosage. Various time-temperature combinations were examined to achieve the most marked synergistic cell-killing effect when combined with propolis. Notably, our TC-HT parameters alone did not damage the cells, which makes thermal therapy safer and more feasible.

In the present study, the results demonstrated for the first time that TC-HT has a synergistic cytotoxic effect with a natural compound, propolis, on the human pancreatic cancer cell line PANC-1. The results indicated that TC-HT augmented propolis-induced apoptotic cell-killing and cell inhibition through the mitochondria-dependent apoptosis pathway and $\mathrm{G} 2 / \mathrm{M}$ phase arrest. The TC methodology was introduced as an efficient manner to avoid unwanted cell damage in HT therapy. These findings indicated that combining TC-HT with propolis is a promising thermal therapy strategy, which sheds light on novel anticancer treatments combining TC-HT with other natural compounds.

\section{Materials and methods}

Cell culture and treatment. PANC-1 and AsPC-1 pancreatic cancer cells, and the normal human embryonic skin cell line Detroit 551, were obtained from the Bioresource Collection and Research Center. Normal human pancreatic duct H6c7 cells were obtained from Kerafast, Inc. PANC-1, AsPC-1 and Detroit cells were maintained in DMEM (PANC-1), RPMI-1640 medium (AsPC-1) or EMEM (Detroit 551) (all from HyClone; GE Healthcare Life Sciences) supplemented with $10 \%$ fetal bovine serum (HyClone; GE Healthcare Life Sciences) and $1 \%$ penicillin-streptomycin. H6c7 cells were maintained in keratinocyte-serum free medium (Invitrogen; Thermo Fisher Scientific, Inc.) supplemented with human recombinant epidermal growth factor, bovine pituitary extract (Invitrogen; Thermo Fisher Scientific, Inc.), and 1\% (v/v) penicillin and streptomycin. All cells were maintained in a humidified incubator with $5 \% \mathrm{CO}_{2}$ and $95 \%$ air at $37^{\circ} \mathrm{C}$.
Liquid bee propolis was purchased from Grandhealth ${ }^{\mathrm{TM}}$. The Thermal Cycler (model 2720) was purchased from Applied Biosystems; Thermo Fisher Scientific, Inc. Cells were plated in 24-well plates or 3-cm culture dishes $24 \mathrm{~h}$ before treatment with or without TC-HT and/or propolis. Propolis was added for $1 \mathrm{~h}$ before TC-HT treatment. In the present study, TC-HT was performed using a modified PCR system. The cells were heated to the desired high temperature followed by a cooling period, and this protocol was repeated for different numbers of cycles. The actual temperatures sensed by the cancer cells were measured by a needle thermocouple. During the TC-HT treatment ( $30 \mathrm{~min})$, the control and treated groups were in ambient conditions at room temperature (RT). Upon treatment, the cells were maintained in the cell culture incubator for an additional $72 \mathrm{~h}$.

Cell viability assay. Cells were seeded at a density of $2 \times 10^{4}$ cells/well in 24 -well plates. After treatment, cell viability was determined by MTT assay. In brief, the medium was replaced with MTT solution $(0.5 \mathrm{mg} / \mathrm{ml}$ in DMEM) and incubated at $37^{\circ} \mathrm{C}$ for $4 \mathrm{~h}$. The supernatants were discarded, and dimethyl sulfoxide was added to dissolve the formazan crystals. The optical density in each well was then evaluated by the measurement of absorbance at $570 \mathrm{~nm}$ using a FLUOstar OPTIMA microplate reader (BMG Labtech, Ltd.). The cell viability was calculated based on the intensity of the formazan, and was expressed as a percentage of the untreated controls, which were set at $100 \%$.

Cellular growth assay. The long-term cell killing effect of the combination treatment was assessed by colony formation area. PANC-1 cells were seeded at a density of $2 \times 10^{4}$ cells/dish in 3 -cm culture dishes $24 \mathrm{~h}$ before being treated with or without TC-HT and/or $0.2 \%$ propolis. Upon treatment, the cells were continuously cultured for 10 days. Cells were stained with $0.5 \%$ crystal violet in methanol for $5 \mathrm{~min}$ at RT, washed with PBS, and images were captured. The colony area was measured using the 'ColonyArea' plugin in ImageJ software (version 1.49j; National Institutes of Health) (22). The sums of the pixel depth over the region of interest were calculated and are represented as arbitrary units. The actual units of colony formation area were $\mathrm{cm}^{2}$.

Flow cytometric detection of apoptotic cells. Apoptotic cells were analyzed by flow cytometry with an Annexin V-FITC and propidium iodide (PI) double-staining kit (BD Biosciences). Cells used for flow cytometry were collected by trypsinization and resuspended in $100 \mu 11 \mathrm{X}$ binding buffer containing Annexin V and PI. Cells were stained for $15 \mathrm{~min}$ at $25^{\circ} \mathrm{C}$ in the dark before being analyzed by flow cytometry. All the cytometry data in the present study were acquired with a BD FACSVerse flow cytometer and analyzed using FlowJo software (version 10.0.7; Tree Star, Inc.).

Immunofluorescence microscopy. Cells were seeded on $20 \mathrm{~mm}$ coverslips in 6-well plates at a density of $2 \times 10^{4}$ cells/well for $24 \mathrm{~h}$ and then treated with TC-HT and/or propolis. Next, cells were washed with PBS and fixed with $4 \%$ paraformaldehyde (Sigma-Aldrich; Merck KGaA) in PBS for $20 \mathrm{~min}$ at RT. Fixed cells were then permeabilized with $0.1 \%$ Triton X-100 
in PBS for $20 \mathrm{~min}$. Nonspecific protein binding was blocked with 2\% BSA (BioShop Canada, Inc.) in PBS for $30 \mathrm{~min}$ at RT. The cells were then incubated with anti- $\beta$-tubulin (cat. no. ab21057; 1:1,500 dilution; Abcam) and anti-active caspase-3 (cat. no. 9661; 1:800 dilution; Cell Signaling Technology, Inc.) primary antibodies overnight at $4^{\circ} \mathrm{C}$. After washing three times in PBS, the cells were incubated with Alexa Fluor 488-conjugated donkey anti-goat (cat. no. 705-545-003) and Alexa Fluor 647-conjugated donkey anti-rabbit (cat. no. 711-605-152) secondary antibodies (both 1:500 dilution; Jackson ImmunoResearch Laboratories, Inc.) for $1 \mathrm{~h}$ at $37^{\circ} \mathrm{C}$ in the dark. The coverslips were mounted to slides using mounting medium with DAPI (Abcam). The mounted samples were examined with an inverted laser scanning confocal microscope with a x20 objective (Zeiss LSM 880; Zeiss AG). Images of randomly selected areas were captured for each sample. The integrated fluorescence density was calculated using the ImageJ software. The sums of the pixel density over the region of interest were calculated and are represented as arbitrary units. The actual units of the integrated fluorescence density were candela.

Measurement of mitochondrial membrane potential (MMP). The loss of MMP was determined using the lipophilic cationic fluorescent dye 3,3'-dihexyloxacarbocyanine iodide $\left[\mathrm{DiOC}_{6}(3)\right.$; Enzo Life Sciences, Inc.] (23). Depolarization of MMP results in the loss of $\mathrm{DiOC}_{6}(3)$ from the mitochondria and a decrease in intracellular fluorescence. Cells were harvested and suspended at a density of $1 \times 10^{6}$ cells $/ \mathrm{ml}$ in dye working solution $(1 \mu \mathrm{M}$ dye in culture medium) in the dark. After 15 min of culture at $37^{\circ} \mathrm{C}$, the supernatant was removed by centrifugation, and the cells were gently resuspended in pre-warmed $\left(37^{\circ} \mathrm{C}\right)$ culture medium. Cells labeled with $\operatorname{DiOC}_{6}(3)$ were detected by flow cytometer with the FL1 channel.

Cell cycle analysis. Upon treatment, the cells were collected by trypsinization and fixed in $70 \%$ ethanol overnight at $4^{\circ} \mathrm{C}$. Prior to the analysis, the cells $\left(1 \times 10^{6}\right.$ cells $\left./ \mathrm{ml}\right)$ were washed with cold PBS and treated with RNase A $(0.1 \mathrm{mg} / \mathrm{ml})$ for $20 \mathrm{~min}$ at $37^{\circ} \mathrm{C}$. Subsequently, the cells were stained with PI $(0.2 \mathrm{mg} / \mathrm{ml})$ for $30 \mathrm{~min}$ at RT. The distribution of cell cycle stages was then determined by flow cytometry.

Western blot analysis. The protein expression levels of PANC-1 cells were investigated by western blot analysis. Cells were scraped off from culture dishes in RIPA lysis buffer (EMD Millipore). After centrifugation, the supernatants were collected and the protein concentrations were determined by Bradford protein assay (BioShop, Inc.). Equal amount of proteins $(30 \mu \mathrm{g})$ were resolved on $10 \%$ SDS-PAGE and then transferred onto polyvinylidene fluoride membranes. For the detection of cytochrome $c$ release, the cytosolic fractions were collected via the REAP method (24). Nonspecific antibody binding sites were blocked in 5\% nonfat dry milk in TBS with Tween-20 (TBST; 20 mM Tris-base, pH 7.6; $0.15 \mathrm{M} \mathrm{NaCl}$; and $0.1 \%$ Tween-20) for $1 \mathrm{~h}$ at RT. The blocked membranes were probed with anti-cell division cycle protein 2 (cdc2; cat. no. GTX108120; 1:1,000), anti-actin (cat. no. GTX109639; 1:10,000) (both from GeneTex, Inc.), anti-Bcl-2 (cat. no. 2872; 1:1,000), anti-Bax (cat. no. 2772; 1:1,000), anti-cytochrome $c$ (cat. no. 4272; 1:1,000) (all from Cell Signaling Technology, Inc.) and anti-GAPDH (cat. no. GTX100118; 1:10,000; GeneTex, Inc.) antibodies overnight at $4^{\circ} \mathrm{C}$. The membranes were washed three times with TBST solution and then incubated with horseradish peroxidase-conjugated goat anti-rabbit secondary antibodies (cat. no. 111-035-003; 1:5,000; Jackson ImmunoResearch Laboratories, Inc.) in a blocking solution. Immunoreactivity was visualized with an enhanced chemiluminescence substrate (Advansta, Inc.) and detected with an imaging system (Amersham Imager 600; GE Healthcare Life Sciences). The images were analyzed with Image Lab software (version 6.0.1; Bio-Rad Laboratories, Inc.)

Statistical analysis. The results are expressed as the mean \pm standard deviation, and each data point represents the average from three independent experiments. Analyses were performed using OriginPro 2015 software (OriginLab). Differences in statistical significance were determined by one-way analysis of variance followed by Tukey's post-hoc test. $\mathrm{P}<0.05$ was considered to indicate a statistically significant difference.

\section{Results}

In vitro-applied $\mathrm{TC}$. To apply a $\mathrm{TC}$ with a rapid temperature change, modified PCR equipment was used as the TC controller (Fig. 1B) in the following in vitro experiments. In this design, some protruding parts of the PCR machine and plastic well were cut off so that the bottom of the well could touch the heat sink. The schematic TC settings are shown in Fig. 1A, where the temperature was elevated to the desired HT temperature followed by a cooling period. The actual temperatures sensed by the cancer cells were measured with a needle thermocouple. Fig. 1C and D represent the tumor cell temperature by TC between $46^{\circ} \mathrm{C}$ and three different cooling temperatures and cycle numbers; the temperature was measured every $20 \mathrm{sec}$. As shown in Fig. 1C, the temperature in the tumor cells could be raised from 37 to $44^{\circ} \mathrm{C}$ within 5 min and returned to a relatively safe low temperature $\left(\sim 42^{\circ} \mathrm{C}\right)$ rapidly. The $46-37^{\circ} \mathrm{C}$ parameter setting was selected to mimic the passive cooling process in the human body. The actual cycling temperature of the cancer cells measured by the needle thermocouple was $44-42^{\circ} \mathrm{C}$. In practice, the heating device can be switched off in the cooling process to achieve similar results. For other cycling parameters that require a higher thermal dissipation rate, active cooling devices could be used as pre-cooling, such as liquid cooling blankets containing circulating water with antifreeze (25).

TC-HT enhances the anticancer effect of propolis via the apoptosis pathway in PANC-1 cells. To examine whether TC treatment could enhance the anticancer effect of honeybee propolis, PANC-1 cancer cells were treated with increasing doses of propolis with or without TC-HT treatment. In the TC-HT groups, 5 different TC parameters for 6 cycles were applied $1 \mathrm{~h}$ after propolis administration. The viability of the cancer cells was examined by MTT assay $72 \mathrm{~h}$ after treatment. As shown in Fig. 2A, the viability of PANC-1 pancreas cancer cells decreased in a dose-dependent manner, except at markedly low doses. As shown in Fig. 2B, treatment with TC-HT alone or low doses of propolis had little effect on cell 
A
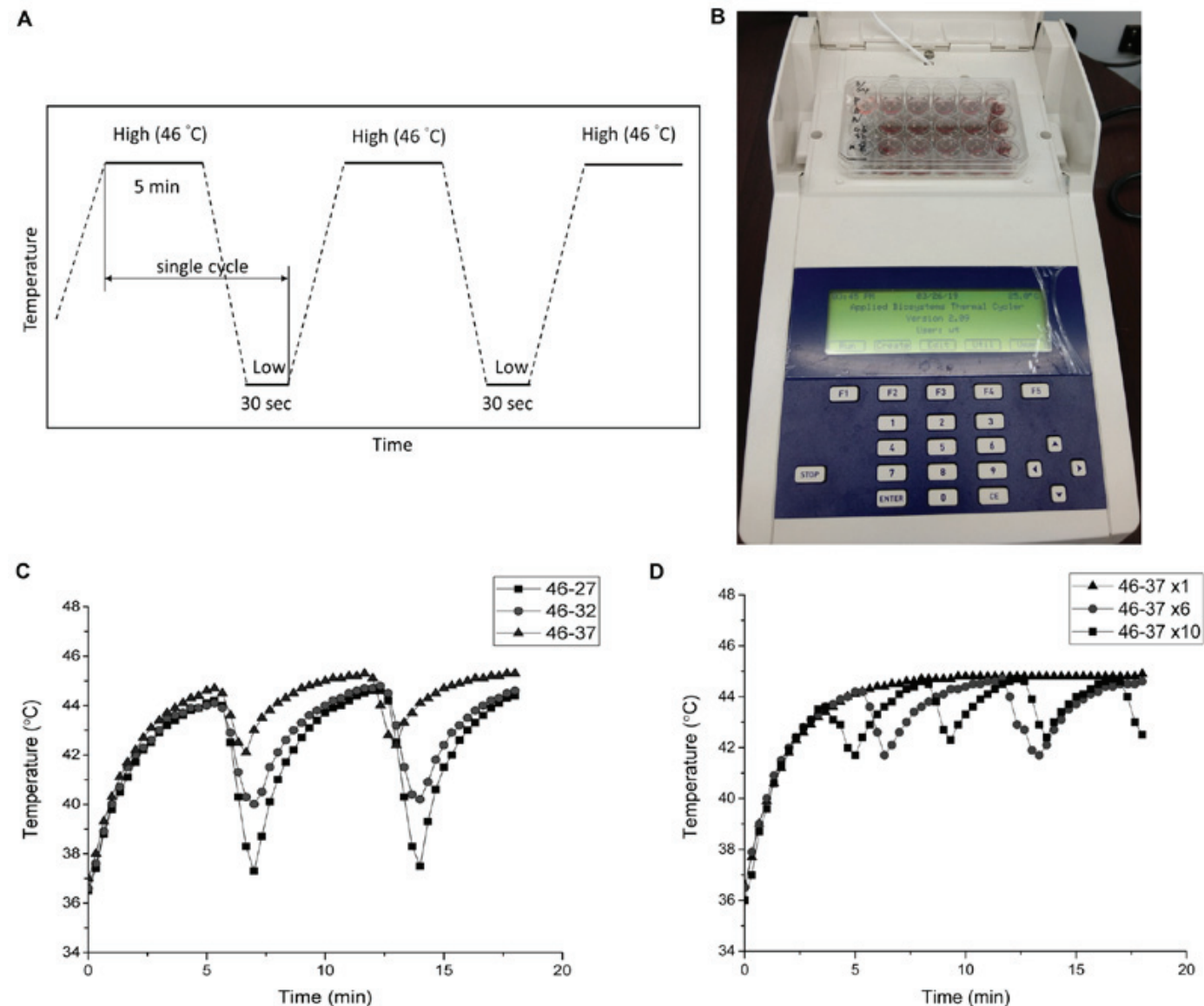

Figure 1. TC-HT with a modified PCR machine. (A) Schematic representation of the TC settings. (B) Image of the TC controller setup. (C) Cell temperature with different cooling temperatures (as monitored by a needle thermocouple located in the bottom of the well). (D) Cell temperature with different cycle numbers. TC-HT, thermal cycle-hyperthermia.

A

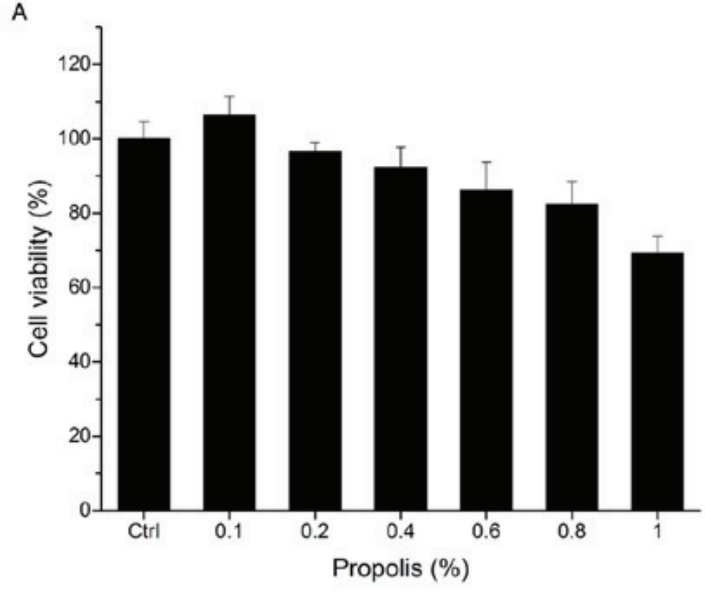

C

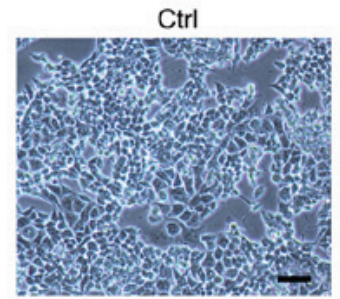

Propolis
B
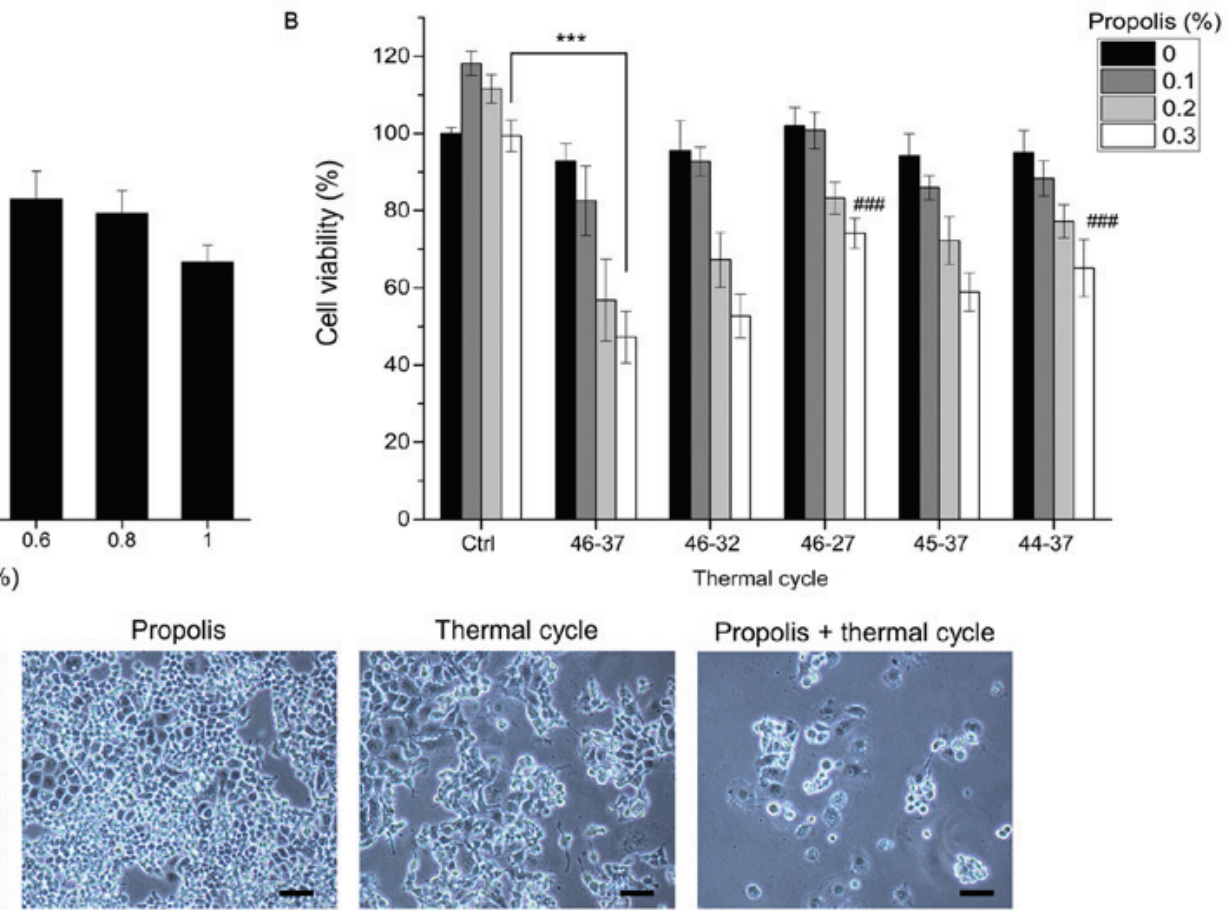

Thermal cycle

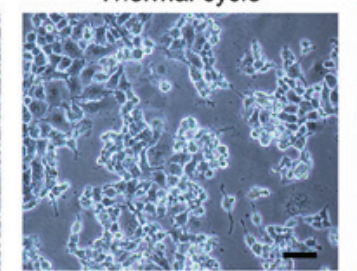

Propolis + thermal cycle

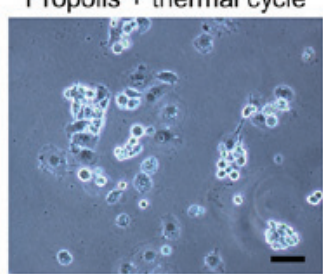

Figure 2. Viability and light microscopy images of PANC-1 cells. (A) Dose-response curve of PANC-1 cells treated with different concentrations of propolis for $72 \mathrm{~h}$. (B) PANC-1 cells were treated with different TC-HT high temperatures and low temperatures with or without propolis for $72 \mathrm{~h}$ and then the residual cell viability was measured by MTT assay. (C) Representative bright field images of PANC-1 cells after treatment with TC-HT and $0.2 \%$ propolis for $72 \mathrm{~h}$. Scale bar, $100 \mu \mathrm{m}$. Data represent the mean \pm standard deviation $(\mathrm{n}=3){ }^{* * *} \mathrm{P}<0.001$; ${ }^{* \# \#} \mathrm{P}<0.001$ vs. cells treated with combined $46-37^{\circ} \mathrm{C}$ TC-HT and $0.3 \%$ propolis. TC-HT, thermal cycle-hyperthermia; Ctrl, control. 


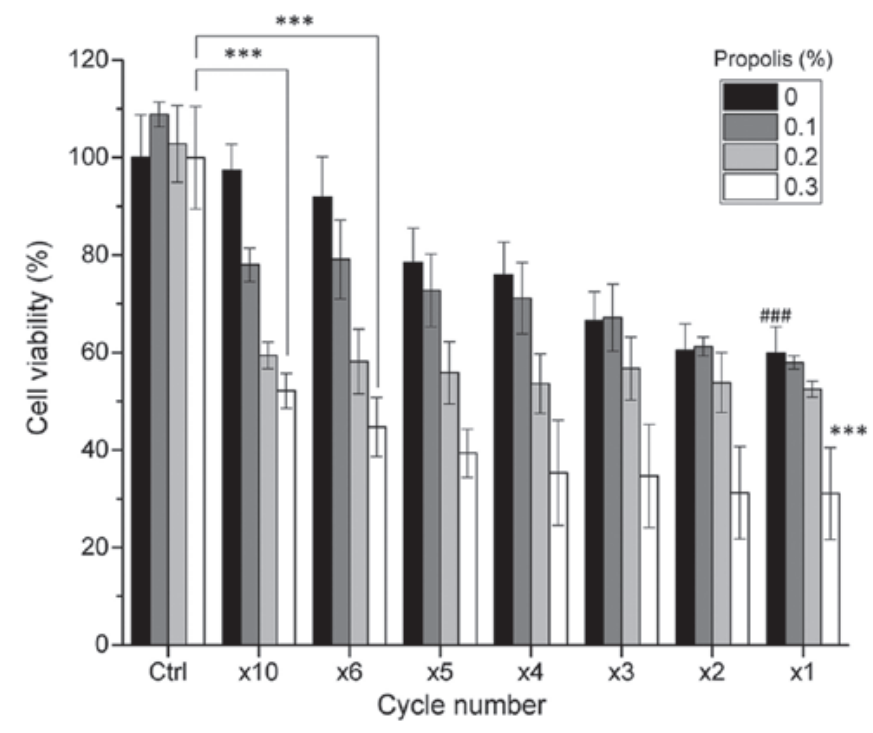

Figure 3. Effect of different TC cycle numbers on the inhibitory effect of TC-HT in PANC-1 cells when combined with propolis. The total thermal dosage was divided into different cycles. In the $\mathrm{x} 1$ cycle group, a high temperature of $46^{\circ} \mathrm{C}$ was sustained for $30 \mathrm{~min}$ continuously. Data represent the mean \pm standard deviation $(\mathrm{n}=3) .{ }^{* * *} \mathrm{P}<0.001 ;{ }^{\# \#} \mathrm{P}<0.001$ vs. control without treatment. TC-HT, thermal cycle-hyperthermia; Ctrl, control.

viability compared with control cells. However, when TC-HT treatment was combined with a low dosage of propolis, the viability of PANC-1 cells was significantly reduced. The most effective parameter was the $46-37^{\circ} \mathrm{C}$ cycling, showing a $>50 \%$ enhancement in cell killing compared with the single treatment. Light microscopy images also revealed a marked inhibitory effect in cells subjected to the combination of TC-HT and $0.2 \%$ propolis after $72 \mathrm{~h}$ of treatment (Fig. 2C). To elucidate the effect of different TC parameters on cell viability, different high temperatures and low temperatures were used in the experiments and the results are shown in Fig. 2B. The results revealed that $46-37^{\circ} \mathrm{C}$ (which led to an actual cycling temperature in the cancer cells of $44-42^{\circ} \mathrm{C}$, as measured by needle thermocouple) was the best temperature cycling parameter against PANC-1 cancer cells. For other cancer cell lines, one could modulate the temperature cycle parameters to achieve the desire therapeutic effect. The present study also compared the effect of different cycle numbers in combination with propolis on the viability of PANC-1 cells (Fig. 3), in which the total thermal dosage was divided into different cycles. For example, 6 cycles (x6) means that the high temperature of $46^{\circ} \mathrm{C}$ was sustained for $5 \mathrm{~min}$ (with the actual PANC-1 cell temperature being $44^{\circ} \mathrm{C}$ ), followed by a cooling period, and this process was repeated six times. In the $\mathrm{x} 1$ cycle group (or the HT group), a high temperature of $46^{\circ} \mathrm{C}$ was sustained for $30 \mathrm{~min}$ uninterruptedly. The results revealed that the viability of PANC-1 cells was cycle-dependent and decreased as the cycle number decreased. Although HT (x1 cycle) in combination with propolis induced the maximum cell death, heat alone exerted marked cytotoxicity towards the cells. In the x10 and x6 groups, the cell viability was $>90 \%$ when the cells were treated with TC-HT alone, while TC-HT in combination with propolis also caused a notable decrease in PANC-1 cell viability (Fig. 3). It was found that the $\mathrm{x} 10 \mathrm{TC}-\mathrm{HT}$ combined with propolis caused a $>45 \%$ decrease in PANC-1 cell viability.
Notably, the combination of $\mathrm{x} 6 \mathrm{TC}-\mathrm{HT}$ and propolis further caused $>50 \%$ inhibitory effect on PANC-1 cells. Therefore, the x6 cycle was selected for subsequent experiments. A dose of $0.2 \%$ propolis was selected for subsequent analyses because excessive cell loss would adversely affect the subsequent experiments. To compare the short-term (compared to $72 \mathrm{~h}$ ) and long-term effects of the combination treatment, an MTT assay at $36 \mathrm{~h}$ and a cellular growth assay at 10 days after the combination treatment were performed. The results revealed that the combination treatment suppressed the growth of PANC-1 cancer cells (Fig. 4A), and apoptosis proceeded after $36 \mathrm{~h}$ (Fig. 4B). To further demonstrate the specificity of the combination treatment, another human pancreatic cancer cell line, namely AsPC-1, normal human embryonic skin Detroit 551 cells and normal human pancreatic duct H6c7 cells were selected for comparison with the pancreatic cancer cell line PANC-1. The results revealed that the combination treatment also had inhibitory effects on AsPC-1 cancer cells (Fig. 4C) but was unharmful to the normal human cell lines Detroit 551 and H6c7 (Fig. 4D). It is worth noting that the effect of the TC parameters used in the present study was less pronounced in AsPC-1 cells than in PANC-1 cells. In order to examine the apoptotic signaling, the $\mathrm{Bax} / \mathrm{Bcl}-2$ ratio was also analyzed in AsPC-1 and H6c7 pancreatic cells (Fig. 4E). Notably, the apoptotic effect on AsPC-1 was less pronounced than that on PANC-1 cells, which is in accordance with the MTT results. Therefore, it was hypothesized that TC parameters are tissue-specific and should be optimized in different cell types. On the contrary, for normal human pancreatic duct H6c7 cells, the results showed that the $\mathrm{Bax} / \mathrm{Bcl}-2$ ratio was only slightly increased in the combined treatment group.

TC-HT enhances propolis-induced apoptosis in PANC-1 cells. To confirm whether TC and propolis treatments decreased cell viability via the induction of apoptosis, PANC-1 cells were cultured with propolis with or without TC-HT treatment and then assessed by flow cytometry. Cells were stained with Annexin V-FITC and PI for detecting apoptotic cells. The cycling parameters were $46-37^{\circ} \mathrm{C}$ for 6 cycles (x6). To elucidate the influence of the duration of high temperature within each cycle on the synergistic anticancer effect, the high temperature duration was doubled to $10 \mathrm{~min}$ and the cycle number was halved to 3 cycles (x3), so that the total high temperature duration was the same. As shown in Fig. 5, propolis alone did not cause apoptosis, which is consistent with the results of the MTT assay. When propolis was combined with TC (x6 or x3), it resulted in $>70 \%$ Annexin V-positive apoptotic cells compared with $5.7 \%$ in the control group (upper right and lower right quadrants). Notably, the x $3 \mathrm{TC}$ protocol resulted in $40.2 \%$ apoptotic cells, while the $\mathrm{x} 6$ protocol did not notably harm the cells.

TC-HT enhances propolis-induced apoptosis. To further examine the mechanism of TC and propolis-induced cell death, the present study investigated the expression of cleaved caspase-3, Bax and Bcl-2 in PANC-1 cells by confocal microscopy and western blotting. Since caspase-3 serves as a convergent downstream of apoptotic events in cells, it is a useful indicator in apoptosis assays. In the present study, PANC-1 cells were stained with anti-cleaved caspase- 3 antibody to identify 


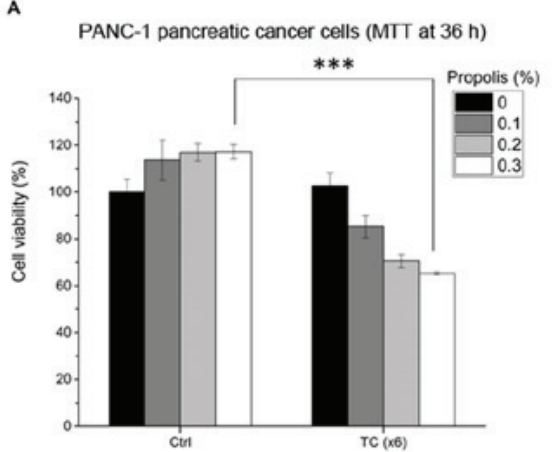

c

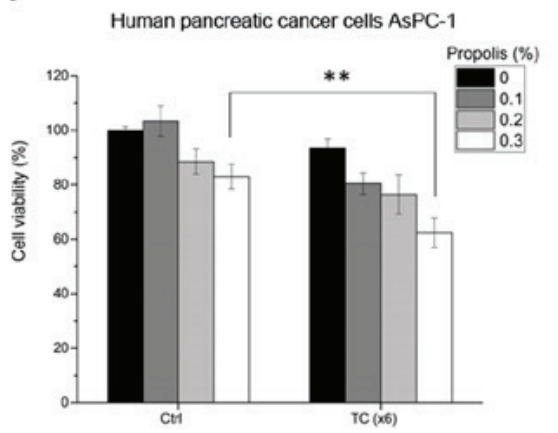

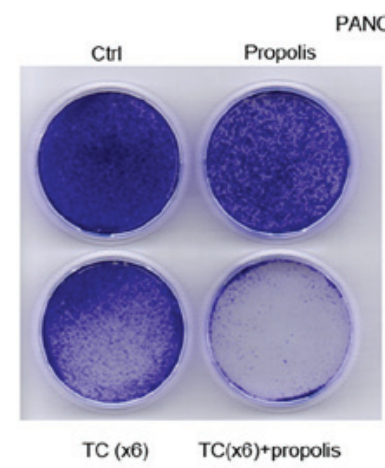

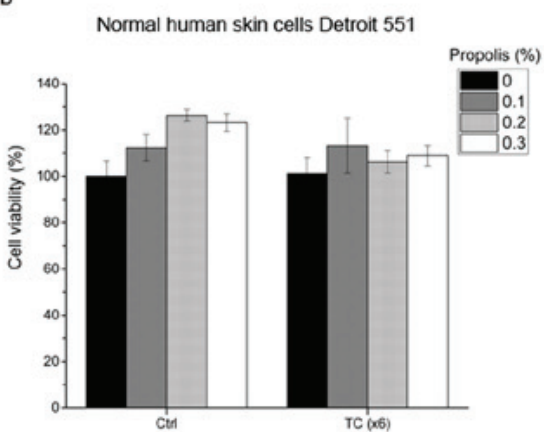

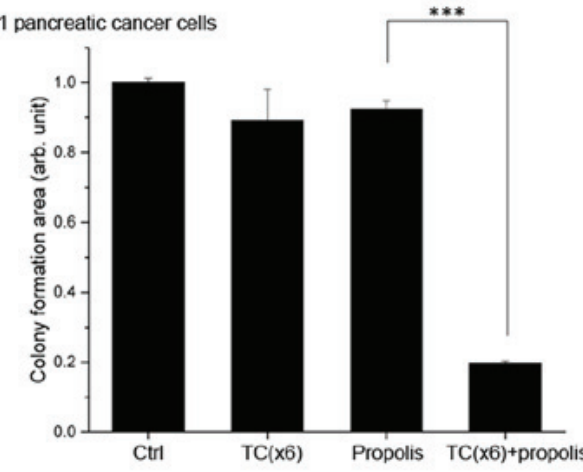

Normal human pancreatic duct cells $\mathrm{H6c7}$
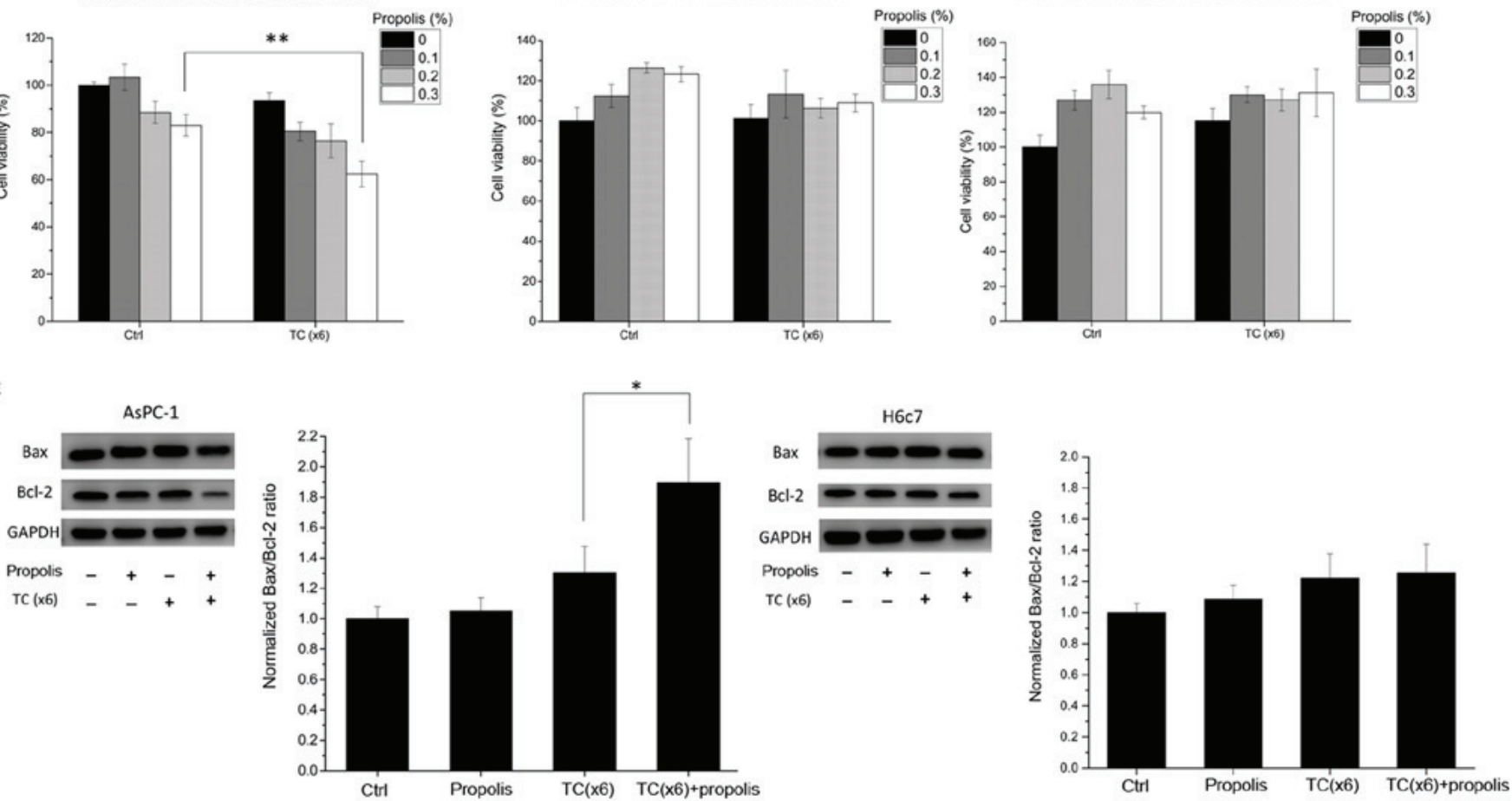

Figure 4. Viability assay and western blot analysis of cancer and normal human cells. (A) MTT assay for PANC-1 cells $36 \mathrm{~h}$ after the treatment. (B) Cellular growth assay for PANC-1 cells 10 days after treatment with propolis and/or TC-HT. (C) MTT assay for AsPC-1 cancer cells. (D) MTT assay for normal human skin cells Detroit 551 and normal human pancreatic duct cells H6c7 following treatment with propolis and/or TC-HT. (E) Western blot analysis of Bax and Bcl-2 protein expression in AsPC-1 and H6c7 cells. Data represent the mean \pm standard deviation $(\mathrm{n}=3) .{ }^{*} \mathrm{P}<0.05,{ }^{* *} \mathrm{P}<0.01$ and ${ }^{* * * *} \mathrm{P}<0.001$. TC-HT, thermal cycle-hyperthermia; Ctrl, control.

the apoptotic cells, and the cell shape was outlined with a $\beta$-tubulin marker, while the nuclei of the cells were visualized with DAPI. As seen in Fig. 6A and B, the combined treatment of $\mathrm{x} 6 \mathrm{TC}-\mathrm{HT}$ and $0.2 \%$ propolis resulted in a marked increase in cleaved caspase- 3 immunostaining. By contrast, there was only a negligible increase in the cleaved caspase-3 signal with TC-HT or propolis treatment alone. The Bcl-2 family is an important regulator of the mitochondria-dependent apoptosis pathway. The Bax/Bcl-2 ratio can be used to assess the upregulation of the apoptotic signaling pathway. The results of the western blotting (Fig. 6C) indicated that the Bax/Bcl-2 ratio was significantly increased in the combined treatment group, suggesting that TC-HT and propolis could trigger the mitochondria-dependent apoptosis pathway.

Effects of TC-HT and propolis on MMP in PANC-1 cells. During apoptosis, the MMP decreases, causing the release of cytochrome $c$ and other apoptotic factors (26).
To address the possibility that the synergistic anticancer effect of TC-HT in combination with propolis could be associated with the mitochondria-dependent apoptosis pathway, the MMP was assessed by flow cytometry and the cytochrome $c$ release was detected by western blotting. Cells were pre-treated with propolis and/or TC-HT and then collected for further analyses. The MMP was detected using a mitochondria-specific probe, namely $\mathrm{DiOC}_{6}(3)$. As shown in Fig. 7A and B, treatment with $\mathrm{x} 6 \mathrm{TC}-\mathrm{HT}$ or $0.2 \%$ propolis alone did not affect the MMP. However, the combined treatment of TC-HT and $0.2 \%$ propolis markedly increased the number of cells exhibiting a loss in MMP, as indicated by a lower $\mathrm{DiOC}_{6}(3)$ intensity. The collapse of the MMP leads to the opening of the mitochondrial permeability transition pores, and the subsequent release of cytochrome $c$ in the cytosol. The results of the western blotting showed that the cytosolic cytochrome $c$ level was significantly increased in the combined treatment group (Fig. 7C). 
A
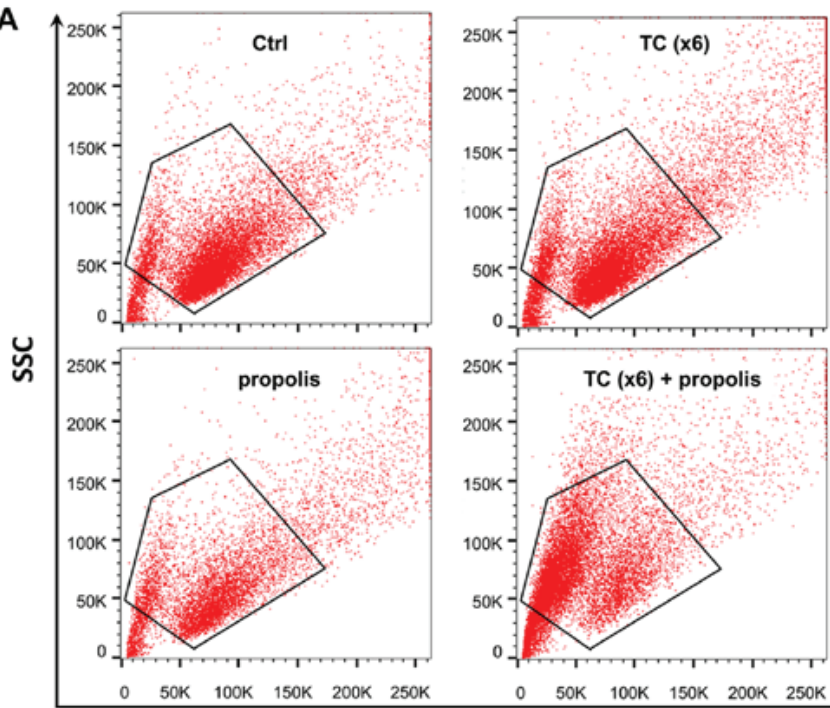

FSC
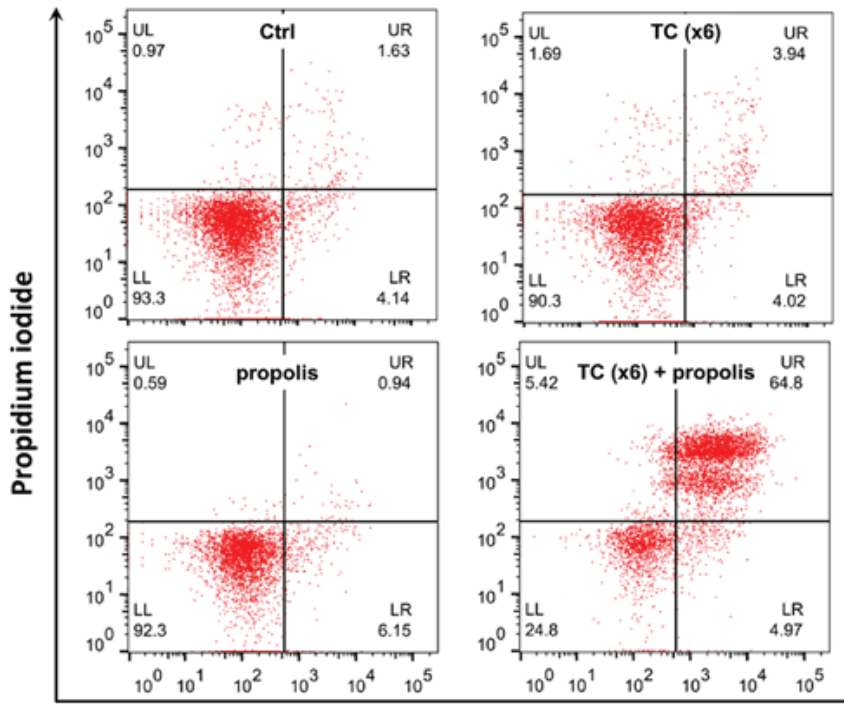

$10^{5} \sqrt{\text { UL }}$ TC $(x 6)+$ propolis $\underset{64.8}{\text { UR }}$

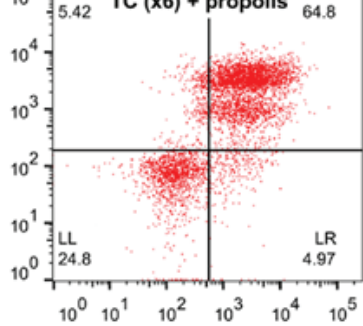

Annexin V-FITC
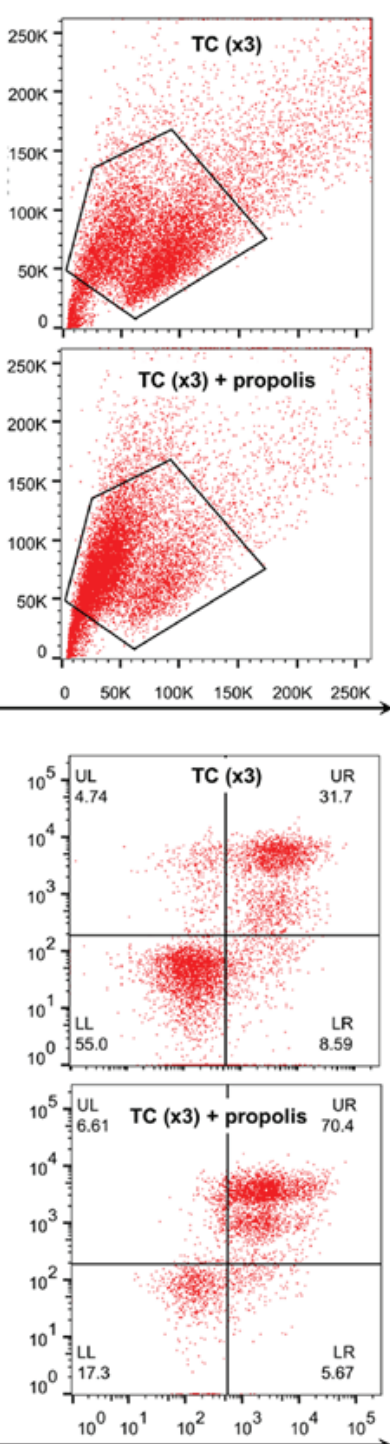

B

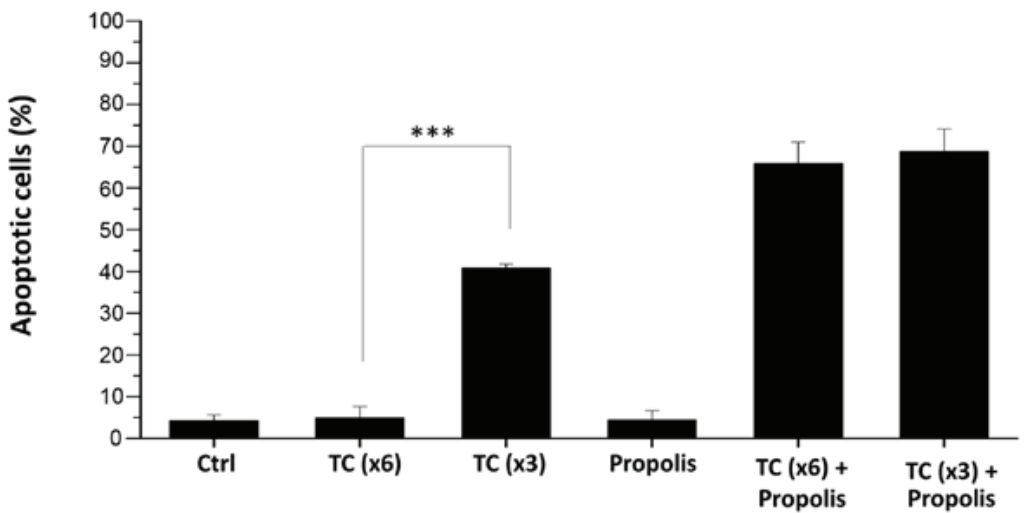

Figure 5. In vitro assessment of apoptosis via Annexin V-FITC/PI double staining. (A) PANC-1 cells were treated with $0.2 \%$ propolis and $\mathrm{x} 3$ or $\mathrm{x} 6 \mathrm{TC}-\mathrm{HT}$ alone or in combination for $72 \mathrm{~h}$, and then assessed by flow cytometric analysis of Annexin V-FITC and PI staining. Cells were gated by FSC/SSC plot to exclude cell debris. (B) Quantification of apoptotic cells. The cells in the LR and UR quadrants indicate Annexin V-positive apoptotic cells. Data represent the mean \pm standard deviation $(\mathrm{n}=3) .{ }^{* * *} \mathrm{P}<0.001$. PI, propidium iodide; TC-HT, thermal cycle-hyperthermia; Ctrl, control; SSC, side scatter; FSC, forward scatter; LR, lower right; UR, upper right; LL, lower left; UL, upper left.

Combination of TC-HT and propolis causes PANC-1 cell arrest at the G2/M phase. Cell cycle arrest is an important target in cancer therapy, since it is critical in the growth and development of tumors. In order to determine whether the cause of cell growth inhibition observed in the viability assay was associated with cell cycle arrest, the DNA content of the cells was analyzed by PI staining followed by flow cytometry. After $72 \mathrm{~h}$ of treatment with TC and/or propolis, the cell cycle phase was determined by flow cytometry. As shown in Fig. 8A, the combination of TC-HT and propolis induced 
A

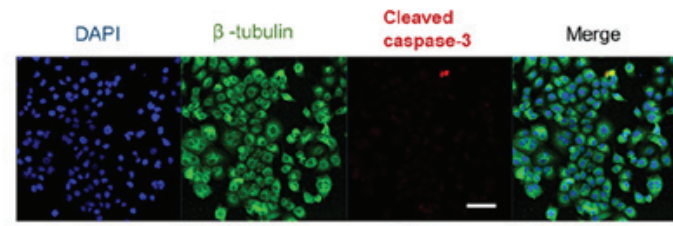

Propolis

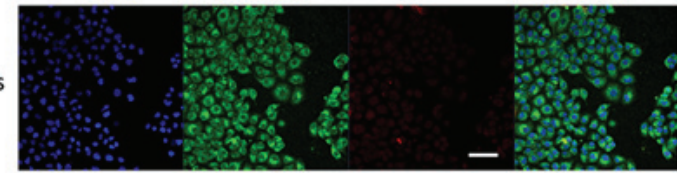

TC (x6)
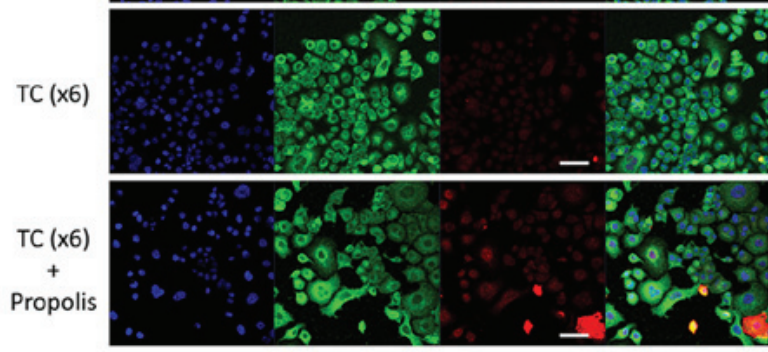

C

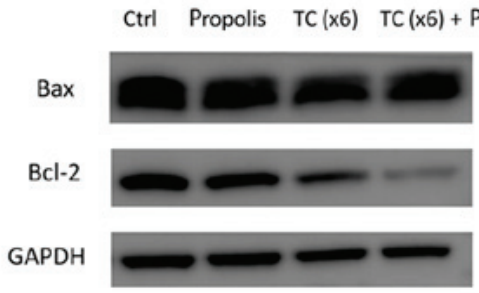

B
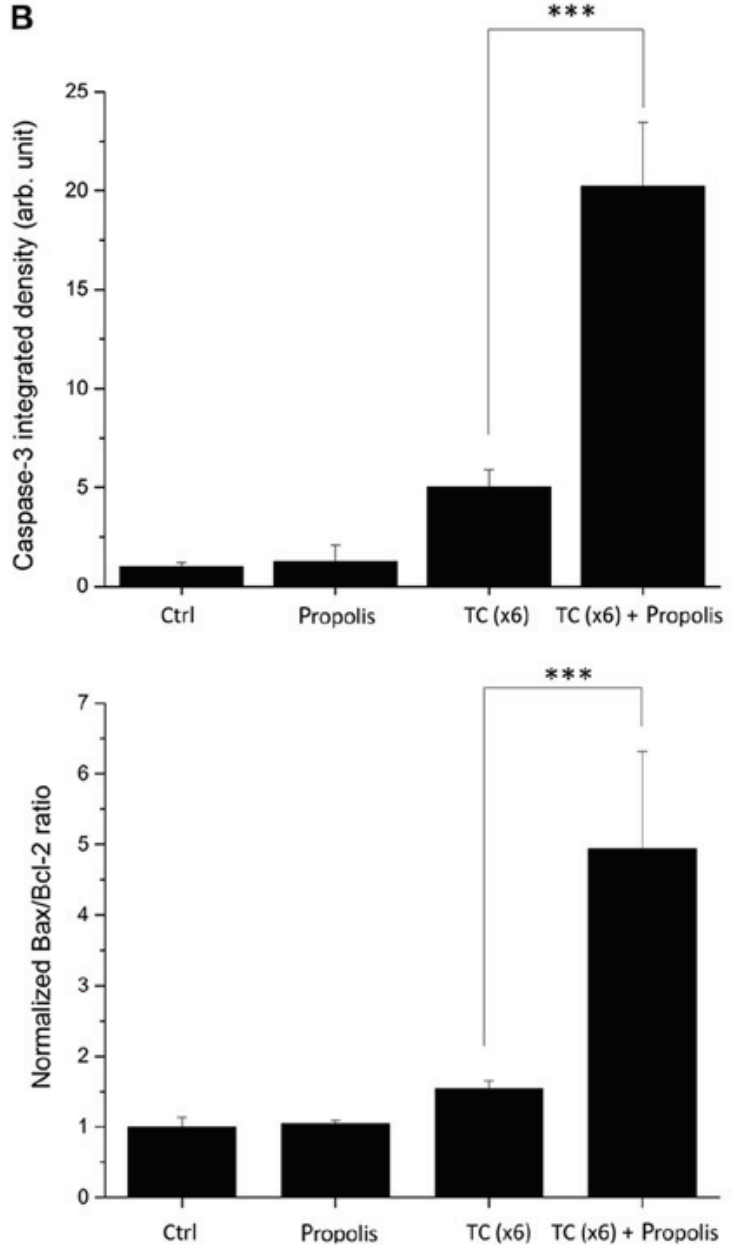

Figure 6. Effect of TC and propolis on active caspase-3 and Bax/Bcl-2 expression. (A) Confocal images of PANC-1 cells treated with $0.2 \%$ propolis and $\mathrm{x} 6$ TC-HT alone or in combination for $72 \mathrm{~h}$. Red fluorescence represents active caspase-3 staining; cell shape was marked with a $\beta$-tubulin marker exhibiting green fluorescence, while the nuclei were labeled with DAPI. Scale bar, $50 \mu \mathrm{m}$. (B) Quantification of caspase-3 expression. (C) Western blot analysis of Bax and Bcl-2 protein expression. Data represent the mean \pm standard deviation $(\mathrm{n}=3){ }^{*}{ }^{* * *} \mathrm{P}<0.001$. TC-HT, thermal cycle-hyperthermia; $\mathrm{Ctrl}$, control.

an accumulation of cells in the $\mathrm{G} 2 / \mathrm{M}$ phase, changing from $20.1 \%$ in the control group to $33.2 \%$ in the group subjected to the $\mathrm{x} 6$ protocol, with a concurrent decline in the number of cells at the G0/G1 phase from 51.1 to $27.9 \%$. In addition, an increase in the fraction of the sub-G1 population, which is an indication of dying cells, was observed in the TC and propolis co-treated group. To further examine the proteins that regulate cell cycle progression, the effects of TC and propolis on cyclin-dependent kinase 1, also known as cdc2, were subsequently investigated. It is known that the primary participant in the G2/M phase transition is cdc2 protein (27). In the present study (Fig. 8B), cdc2 protein expression was markedly reduced in the combined treatment with x6 TC-HT and $0.2 \%$ propolis group, while either treatment alone did not significantly affect cdc2 expression.

\section{Discussion}

The focus of the present study was to investigate the synergistic anticancer effect of TC-HT and propolis on PANC-1 cells. The anticancer effects of propolis were strongly potentiated by TC administration. This novel TC method was able to enhance the cytotoxicity of propolis by $>10$-fold, while being unharmful to normal cells and efficient as a combination therapy. In fact, in the present results, $>50 \%$ of cancer cells were inhibited or killed by $<1 \mathrm{~h}$ of combination treatment, while the $\mathrm{TC}$ alone hardly harmed the cells.

HT is a promising strategy in combination with conventional therapies to halt tumor growth. It has been proposed that HT could enhance the sensitivity of cancer cells to drug treatment, thereby exhibiting a synergistic anticancer effect (28). The advantage of such combination treatments is the possibility of using minimal doses of chemotherapy and radiation, leading to a maximum curative effect with less unwanted cell damage. Numerous studies have demonstrated the beneficial effect of HT in chemotherapy $(8,11,29)$. However, the unwanted damage caused by HT cannot be effectively controlled and avoided. One major concern is that the thermal dosage applied to tumor cells may also harm normal tissue cells. Previous studies revealed that a sustained temperature $>42^{\circ} \mathrm{C}$ will cause necrosis of living cells $(30,31)$. Besides, heat tolerance will be dissimilar in different tissues (32). Therefore, it is important to select the optimal thermal dosage, as different temperatures and durations may be necessary to achieve the desired outcomes.

The present study provides an efficient way of controlling the applied thermal dosage to cells. The heat-and-cool cycling used in the present study has advantages when combined 
A

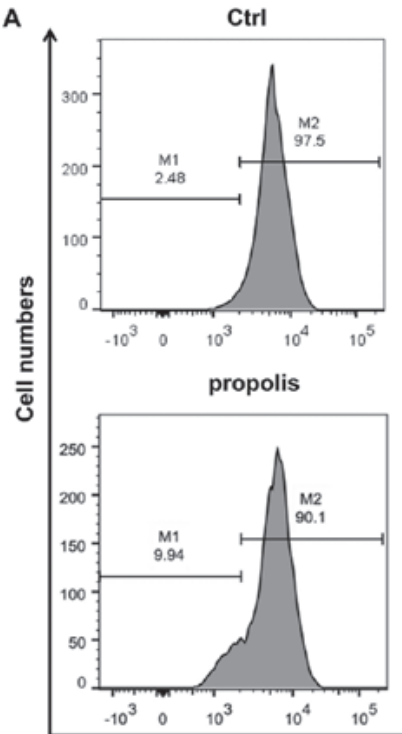

TC ( $\times 6)$

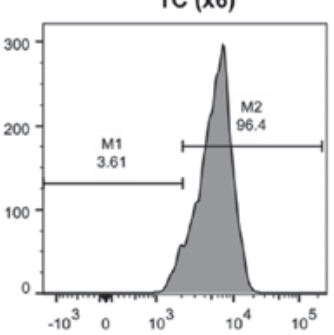

TC (x6) + propolis

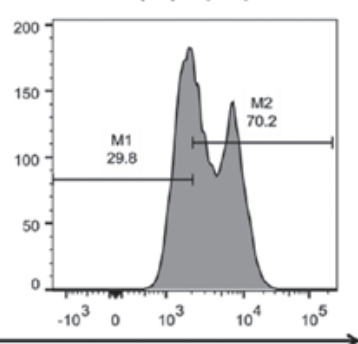

Fluorescence intensity of $\mathrm{DiOC}_{6}(3)$

C
B

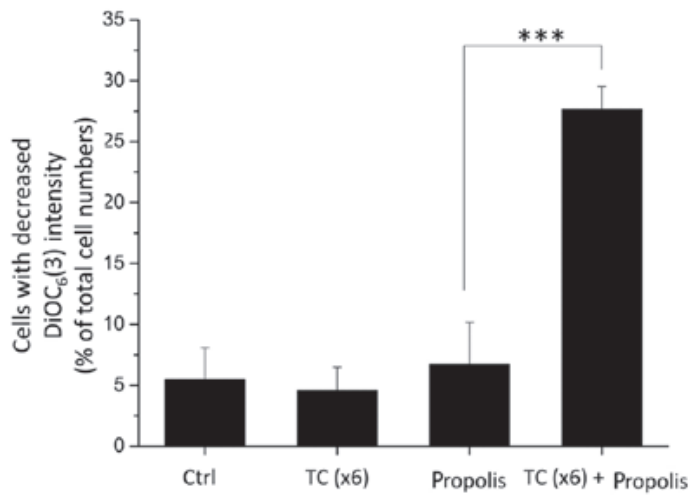
Ctrl Propolis TC (x6) TC (x6) + Propolis Cytochrome c GAPDH

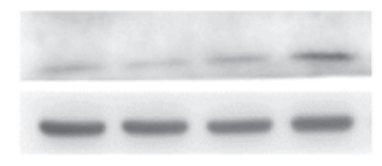

Figure 7. Flow cytometric analysis of MMP in PANC-1 cells treated with TC and propolis. PANC-1 cells were treated with x6 TC-HT and 0.2\% propolis alone or in combination for $72 \mathrm{~h}$. (A) After treatment, the MMP was studied with the use of $\mathrm{DiOC}_{6}(3)$. (B) Quantification of the cells with lower DiOC 6 (3) intensity. (C) Western blot analysis of cytosolic cytochrome $c$. Data represent the mean \pm standard deviation $(\mathrm{n}=3)$. ${ }^{* *} \mathrm{P}<0.01$ and ${ }^{* * *} \mathrm{P}<0.001$. MMP, mitochondrial membrane potential; TC-HT, thermal cycle-hyperthermia; $\mathrm{DiOC}_{6}(3), 3,3$ '-dihexyloxacarbocyanine iodide; Ctrl, control.

with anticancer compounds or chemotherapy drugs. During the heating process, the temperature was elevated to a certain threshold and maintained for a specific period, which can synergize with anticancer drugs. In the cooling process, the tissue cell temperature was lowered to prevent excessive thermal dosage accumulation and subsequent cytotoxic cell damage. The heat-and-cool process can be repeated numerous times to achieve the desired anticancer effect. As shown in Fig. 2B, three different maximum thermal cycling temperatures for 6 cycles were applied upon administration of propolis. The most effective parameter setting was $46-37^{\circ} \mathrm{C}$ cycling (notably, the actual cycling temperature of the cancer cells measured with the needle thermocouple was $44-42^{\circ} \mathrm{C}$ ), which mimics the passive cooling process in the human body. The results indicated that there was a specific threshold temperature for maximizing the cytotoxic anticancer effect of propolis. Furthermore, as shown in Fig. 2B, an excessively low temperature in the cooling process will diminish the synergistic effect, since the total thermal dosage is insufficient to sensitize PANC-1 cells in the cycling procedure. Therefore, it is important to determine the appropriate cycling parameters when combining TC-HT with different anticancer drugs. The results of the present study showed the advantages of TC in preventing cytotoxic damage when the total thermal dosage was divided into different cycles. In the $\mathrm{x} 1$ cycle group, a high temperature of $46^{\circ} \mathrm{C}$ was sustained for $30 \mathrm{~min}$ continuously. Although HT acts synergistically with propolis in killing cancer cells, heat alone also causes severe cytotoxicity. The aim of combination therapy is to avoid the latter. An earlier study analyzed the time-dependent modifications of cancer cells during exposure to HT, and revealed that the survival rate decreased with increasing exposure time (33). Namely, the short exposure of cancer cells to HT may induce cellular stress without affecting cell viability, while prolonged exposure may lead to cell death. The present study demonstrated that the viability of PANC-1 cells was $>90 \%$ in the $x 6$ group when treated with TC-HT alone. Notably, the combination of x6 TC-HT and propolis caused a $>50 \%$ inhibitory effect on PANC-1 cell viability. Moreover, the same combination treatment exerted low cytotoxicity on the normal human cell lines Detroit 551 and H6c7. These data indicated that TC-HT and propolis are promising candidates for anti-pancreatic cancer treatment, with low toxicity towards normal cells.

The molecular mechanisms responsible for this potentiation were investigated by determining the MMP and cell cycle progression. The expression of downstream proteins of the apoptotic pathway and cell cycle regulatory proteins was also 

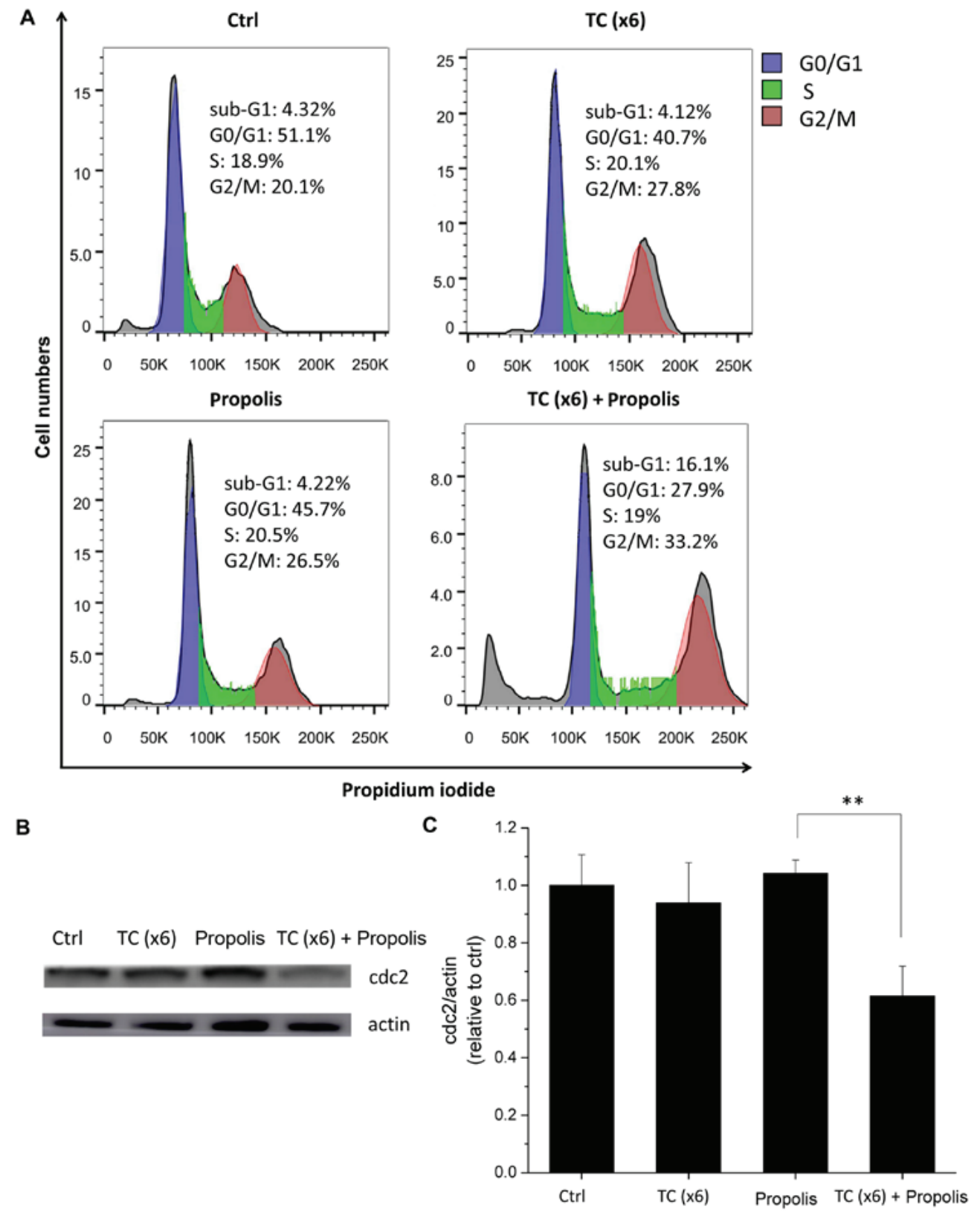

Figure 8. Effect of TC and propolis on PANC-1 cell cycle distribution. PANC-1 cells were treated with $0.2 \%$ propolis and $\mathrm{x} 6 \mathrm{TC}-\mathrm{HT}$ alone or in combination for $72 \mathrm{~h}$. (A) Cell cycle analysis by PI flow cytometry. (B) Western blot analysis of the G2/M phase-regulating protein cdc2. Actin was used to confirm equal protein loading. (C) Quantification of cdc2 expression. Data represent the mean \pm standard deviation $(\mathrm{n}=3)$. ${ }^{* * *} \mathrm{P}<0.01$. TC-HT, thermal cycle-hyperthermia; PI, propidium iodide; cdc2, cell division cycle protein 2; Ctrl, control.

evaluated. Previous in vitro and in vivo studies demonstrated that propolis exerts cytotoxic properties against cancer cells through the mitochondria-mediated apoptosis pathway and cell growth arrest (21). Mitochondria are associated with cell stress responses, including oxidative stress and cell death. During apoptosis, the MMP decreases, causing the release of cytochrome $c$ into the cytosol and the activation of the subsequent caspase cascades (26). In the present study, the combined treatment of TC-HT and propolis greatly suppressed MMP, which is an important index for damage and dysfunction of the mitochondria. In addition, the western blotting results showed that the expression level of cytosolic cytochrome $c$ was significantly higher in the combined treatment group. Moreover, it was found that caspase-3 expression was promoted by the combined treatment. These data indicated that the enhancement of apoptosis mediated by the combined treatment was induced by a mitochondria-dependent apoptosis pathway.

Cancer is characterized by uncontrolled cell division, which is linked to the aberrant activity of various cell cycle regulators. Therefore, cell cycle regulatory proteins are considered attractive targets in cancer therapy. In this study, it was found that the combined treatment of TC-HT and propolis resulted in $\mathrm{G} 2 / \mathrm{M}$ phase arrest. Cell cycle analysis by flow cytometry also demonstrated an increase in the fraction of dying cells, as indicated by the sub-G1 population in the combined treatment group. The main participant in the G2-M transition is CDK1, also known as cdc2. According to the western blotting results, cdc2 expression was downregulated in the combined treatment with propolis and TC group, while neither TC or propolis 
alone interfered with cdc 2 expression. These results indicated that the thermal enhancement of propolis cytotoxicity was mediated in part by inhibition of the kinase activity of cdc2, which prevents cell progression into mitosis. Although there is evidence that TC-HT and propolis result in G2/M phase arrest, it is not possible exclude the possibility that G0/G1-phase cells are more susceptible to treatment. Further studies are required to elucidate the detailed mechanism underlying the increased $\mathrm{G} 2 / \mathrm{M}$ population.

Pancreatic cancer has the highest mortality rate of all cancer types, due in part to the lack of diagnostic tools for early detection. Treatment options are limited and mostly rely on chemotherapy or radiation. In pancreatic cancer, the effects of chemotherapy combined with HT using several heating methods and technologies have been investigated in clinical settings, such as whole body HT and HT intraperitoneal chemotherapy (34-37). Previous studies have demonstrated the benefits of HT, which can enhance the cytotoxicity of chemotherapy drugs towards pancreatic cancer (38-40). The present study provides a novel methodology in HT therapy, namely TC-HT therapy, which is safer and has more feasible administration when combined with anticancer compounds. The present results directly confirmed that, by thermally cycling the pancreatic cancer cells and administering propolis, significant cytotoxic and inhibitory effects were observed. The present study used PCR equipment to demonstrate TC-HT in vitro. For in vivo or clinical experiments, other heating strategies must be used and tested, such as high-intensity focused ultrasound (HIFU) (41). HIFU has been widely used as a hyperthermal technique. It can be used for thermal ablation as well as for producing mild HT in cancer (42). The thermal parameters may be finely tuned by modulating the heating power and the size of the heated volume to meet the specific requirement for the application of mild HT therapy in vivo (43). It was hypothesized that TC-HT will be a promising strategy that could be applied to pancreatic cancer, and thereby may be able to improve the quality of life of the majority of patients with pancreatic cancer.

In summary, the present study demonstrated a novel methodology in HT therapy, namely the TC-HT technique. The heat-and-cool cycling can create a therapeutic window with a maximum synergistic effect when combined with natural compounds, with minimal unwanted cell damage. This would allow for repeated and long-term treatments without the limitations associated with the accumulation of toxic cell damage. The present results confirmed that TC and propolis could synergistically inhibit PANC-1 cancer cell growth through the mitochondria-dependent apoptosis pathway and cell cycle arrest. It is thought that this strategy could be extended to other HT therapies in the fight against cancer. Further studies are required to examine the association between specific TC parameters and different anticancer drugs to optimize the curative effects.

\section{Acknowledgements}

The authors would like to acknowledge the service provided by Mrs. J. Y. Tsai at the Research Core Facilities 3 Laboratory of the Department of Medical Research at National Taiwan University Hospital.

\section{Funding}

The present study was supported by grants from the Ministry of Science and Technology (grant no. 105-2112-M-002-006-MY3 awarded to CYC) and the Ministry of Education (grant no. MOE 106R880708 to CYC) of Taiwan, R.O.C.

\section{Availability of data and materials}

The datasets used and/or analyzed during the current study are available from the corresponding author on reasonable request.

\section{Authors' contributions}

CYC initiated the study, conceived the experiments and managed the project. WTC and CYC wrote the manuscript. WTC, YKS, CHL and CYC performed experiments and analyzed the data. All authors read and approved the final version of the manuscript.

\section{Ethics approval and consent to participate}

Not applicable.

\section{Patient consent for publication}

Not applicable.

\section{Competing interests}

The authors declare that they have no competing interests.

\section{References}

1. van den Tempel N, Horsman MR and Kanaar R: Improving efficacy of hyperthermia in oncology by exploiting biological mechanisms. Int J Hyperthermia 32: 446-454, 2016.

2. Mantso T, Goussetis G, Franco R, Botaitis S, Pappa A and Panayiotidis M: Effects of hyperthermia as a mitigation strategy in DNA damage-based cancer therapies. Semin Cancer Biol 37-38: 96-105, 2016

3. Chu KF and Dupuy DE: Thermal ablation of tumours: Biological mechanisms and advances in therapy. Nat Rev Cancer 14: 199-208, 2014.

4. Paulson JR, Kresch AK and Mesner PW: Moderate hyperthermia induces apoptosis in metaphase-arrested cells but not in interphase Hela cells. Adv Biol Chem 6: 126-139, 2016.

5. Lim CU, Zhang Y and Fox MH: Cell cycle dependent apoptosis and cell cycle blocks induced by hyperthermia in HL-60 cells. Int J Hyperthermia 22: 77-91, 2006.

6. Bhowmick S, Coad JE, Swanlund DJ and Bischof JC: In vitro thermal therapy of AT-1 Dunning prostate tumours. Int J Hyperthermia 20: 73-92, 2004.

7. Sminia P, van der Zee J, Wondergem J and Haveman J: Effect of hyperthermia on the central nervous system: A review. Int J Hyperthermia 10: 1-30, 1994.

8. Schaaf L, Schwab M, Ulmer C, Heine S, Mürdter TE, Schmid JO, Sauer G, Aulitzky WE and van der Kuip H: Hyperthermia synergizes with chemotherapy by inhibiting PARP1-dependent DNA replication arrest. Cancer Res 76: 2868-2875, 2016.

9. Miyamoto R, Oda T, Hashimoto S, Kurokawa T, Inagaki Y, Shimomura O, Ohara Y, Yamada K, Akashi Y, Enomoto T, et al: Cetuximab delivery and antitumor effects are enhanced by mild hyperthermia in a xenograft mouse model of pancreatic cancer. Cancer Sci 107: 514-520, 2016.

10. Man J, Shoemake JD, Ma T, Rizzo AE, Godley AR, Wu Q, Mohammadi AM, Bao S, Rich JN and Yu JS: Hyperthermia sensitizes glioma stem-like cells to radiation by inhibiting AKT signaling. Cancer Res 75: 1760-1769, 2015. 
11. Schaaf L, van der Kuip H, Zopf W, Winter S, Münch M, Mürdter TE, Thon KP, Steurer W, Aulitzky WE and Ulmer C: A temperature of $40^{\circ} \mathrm{C}$ appears to be a critical threshold for potentiating cytotoxic chemotherapy in vitro and in peritoneal carcinomatosis patients undergoing HIPEC. Ann Surg Oncol 22 (Suppl 3): S758-S765, 2015.

12. Krawczyk PM, Eppink B, Essers J, Stap J, Rodermond H, Odijk H, Zelensky A, van Bree C, Stalpers LJ, Buist MR, et al: Mild hyperthermia inhibits homologous recombination, induces BRCA2 degradation, and sensitizes cancer cells to poly (ADP-ribose) polymerase-1 inhibition. Proc Natl Acad Sci USA 108: 9851-9856, 2011.

13. Dewey WC: Arrhenius relationships from the molecule and cell to the clinic. Int J Hyperthermia 10: 457-483, 1994.

14. Ishiai S, Tahara W, Yamamoto E, Yamamoto R and Nagai K: Histone deacetylase inhibitory effect of Brazilian propolis and its association with the antitumor effect in Neuro2a cells. Food Sci Nutr 2: 565-570, 2014.

15. Taira N, Nguyen BCQ, Be Tu PT and Tawata S: Effect of Okinawa propolis on PAK1 activity, Caenorhabditis elegans longevity, melanogenesis, and growth of cancer cells. J Agric Food Chem 64: 5484-5489, 2016.

16. Huang S, Zhang C-P, Wang K, Li GQ and Hu F-L: Recent advances in the chemical composition of propolis. Molecules 19: 19610-19632, 2014.

17. Seydi E, Hosseini SA, Salimi A and Pourahmad J: Propolis induce cytotoxicity on cancerous hepatocytes isolated from rat model of hepatocellular carcinoma: Involvement of ROS-mediated mitochondrial targeting. PharmaNutrition 4: 143-150, 2016.

18. Seda Vatansever H, Sorkun K, Ismet Deliloğlu Gurhan S, Ozdal-Kurt F, Turkoz E, Gencay O and Salih B: Propolis from Turkey induces apoptosis through activating caspases in human breast carcinoma cell lines. Acta Histochem 112: 546-556, 2010.

19. Kouidhi B, Zmantar T and Bakhrouf A: Anti-cariogenic and anti-biofilms activity of Tunisian propolis extract and its potential protective effect against cancer cells proliferation. Anaerobe 16 : 566-571, 2010.

20. Frión-Herrera Y, Díaz-García A, Ruiz-Fuentes J, RodríguezSánchez H and Sforcin JM: Brazilian green propolis induced apoptosis in human lung cancer A549 cells through mitochondrial-mediated pathway. J Pharm Pharmacol 67: 1448-1456, 2015.

21. Demir S, Aliyazicioglu Y, Turan I, Misir S, Mentese A, Yaman SO, Akbulut K, Kilinc K and Deger O: Antiproliferative and proapoptotic activity of Turkish propolis on human lung cancer cell line. Nutr Cancer 68: 165-172, 2016.

22. Guzmán C, Bagga M, Kaur A, Westermarck J and Abankwa D: ColonyArea: An ImageJ plugin to automatically quantify colony formation in clonogenic assays. PLoS One 9: e92444, 2014.

23. Korchak HM, Rich AM, Wilkenfeld C, Rutherford LE and Weissmann G: A carbocyanine dye, $\operatorname{DiOC}_{6}(3)$, acts as a mitochondrial probe in human neutrophils. Biochem Biophys Res Commun 108: 1495-1501, 1982.

24. Suzuki K, Bose P, Leong-Quong RY, Fujita DJ and Riabowol K: REAP: A two minute cell fractionation method. BMC Res Notes 3: 294-294, 2010

25. Vaity C, Al-Subaie $\mathrm{N}$ and Cecconi M: Cooling techniques for targeted temperature management post-cardiac arrest. Crit Care 19: 103, 2015.

26. Cai J, Yang J and Jones D: Mitochondrial control of apoptosis: The role of cytochrome $c$. Biochimica et Biophysica Acta (BBA). Bioenergetics 1366: 139-149, 1998.

27. Park M, Chae H-D, Yun J, Jung M, Kim YS, Kim SH, Han MH and Shin DY: Constitutive activation of cyclin B1-associated cdc2 kinase overrides p53-mediated G2-M arrest. Cancer Res 60: $542-545,2000$

28. Kampinga HH: Cell biological effects of hyperthermia alone or combined with radiation or drugs: A short introduction to newcomers in the field. Int J Hyperthermia 22: 191-196, 2006.
29. Hu X, Akutsu Y, Suganami A, Qin W, Hanari N, Murakam K, Kano M, Usui A, Suito H, Takahashi M, et al: Low-dose hyperthermia enhances the antitumor effects of chemotherapy in squamous cell carcinoma. Dis Esophagus 30: 1-7, 2017.

30. Christophi C, Winkworth A, Muralihdaran V and Evans P: The treatment of malignancy by hyperthermia. Surg Oncol 7: 83-90, 1998.

31. Dewey WC: Arrhenius relationships from the molecule and cell to the clinic. Int J Hyperthermia 25: 3-20, 2009.

32. Overgaard K and Overgaard J: Investigations on the possibility of a thermic tumour therapy. I. Short-wave treatment of a transplanted isologous mouse mammary carcinoma. Eur J Cancer 8: 65-78, 1972.

33. Dewey WC, Hopwood LE, Sapareto SA and Gerweck LE: Cellular responses to combinations of hyperthermia and radiation. Radiology 123: 463-474, 1977.

34. Ishikawa T, Kokura S, Sakamoto N, Ando T, Imamoto E, Hattori T, Oyamada H, Yoshinami N, Sakamoto M, Kitagawa K, et al: Phase II trial of combined regional hyperthermia and gemcitabine for locally advanced or metastatic pancreatic cancer. Int J Hyperthermia 28: 597-604, 2012.

35. Ishii $\mathrm{H}$, Okada $\mathrm{S}$, Tokuuye K, Nose H, Okusaka T, Yoshimori M, Nagahama H, Sumi M, Kagami Y and Ikeda H: Protracted 5-fluorouracil infusion with concurrent radiotherapy as a treatment for locally advanced pancreatic carcinoma. Cancer 79: 1516-1520, 1997.

36. Robins HI, Cohen JD, Schmitt CL, Tutsch KD, Feierabend C, Arzoomanian RZ, Alberti D, d'Oleire F, Longo W and Heiss C: Phase I clinical trial of carboplatin and 41.8 degrees $C$ whole-body hyperthermia in cancer patients. J Clin Oncol 11: 1787-1794, 1993.

37. Stephens AD, Alderman R, Chang D, Edwards GD, Esquivel J, Sebbag G, Steves MA and Sugarbaker PH: Morbidity and mortality analysis of 200 treatments with cytoreductive surgery and hyperthermic intraoperative intraperitoneal chemotherapy using the coliseum technique. Ann Surg Oncol 6: 790-796, 1999.

38. Adachi S, Kokura S, Okayama T, Ishikawa T, Takagi T, Handa O, Naito Y and Yoshikawa T: Effect of hyperthermia combined with gemcitabine on apoptotic cell death in cultured human pancreatic cancer cell lines. Int J Hyperthermia 25: 210-219, 2009.

39. Basel MT, Balivada S, Wang H, Shrestha TB, Seo GM, Pyle M, Abayaweera G,Dani R, Koper OB, Tamura M, et al: Cell-delivered magnetic nanoparticles caused hyperthermia-mediated increased survival in a murine pancreatic cancer model. Int J Nanomedicine 7: 297-306, 2012.

40. Wang L, Dong J, Ouyang W, Wang X and Tang J: Anticancer effect and feasibility study of hyperthermia treatment of pancreatic cancer using magnetic nanoparticles. Oncol Rep 27: 719-726, 2012.

41. Partanen A, Tillander M, Yarmolenko PS, Wood BJ, Dreher MR and Köhler MO: Reduction of peak acoustic pressure and shaping of heated region by use of multifoci sonications in MR-guided high-intensity focused ultrasound mediated mild hyperthermia. Med Phys 40: 013301, 2013.

42. Frazier N, Payne A, de Bever J, Dillon C, Panda A, Subrahmanyam N and Ghandehari H: High intensity focused ultrasound hyperthermia for enhanced macromolecular delivery. J Control Release 241: 186-193, 2016.

43. Partanen A, Yarmolenko PS, Viitala A, Appanaboyina S, Haemmerich D, Ranjan A, Jacobs G, Woods D, Enholm J, Wood BJ, et al: Mild hyperthermia with magnetic resonance-guided high-intensity focused ultrasound for applications in drug delivery. Int J Hyperthermia 28: 320-336, 2012.

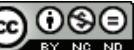

This work is licensed under a Creative Commons Attribution-NonCommercial-NoDerivatives 4.0 International (CC BY-NC-ND 4.0) License. 